Working Paper 86-4

\title{
INTEREST RATE SMOOTHING AND PRICE LEVEL TREND-STATIONARITY
}

\author{
Marvin Goodfriend*
}

Federal Reserve Bank of Richmond

July 1986

*Economist and Vice President, Federal Reserve Bank of Richmond. The paper was partially written in 1983 while I was Visiting Economist with the Econometric and Computer Applications Section at the Board of Governors of the Federal Reserve System. Some material in this paper was circulated previously under the title "Rational Expectations, Interest Rate Smoothing, and the 'Optimality' of a Non-Trend-Stationary Money Supply Rule." 


\section{INTRODUCTION}

For industrial countries in the post-war period, the price level

and the money stock have displayed little tendency to revert to given growth paths. ${ }^{1}$ Indeed, this stylized fact is frequently referred to by monetarist critics of central banks, who point out that periods of temporarily high or low money growth, rather than being subsequently reversed, typically alter the level of the money stock and prices permanently.

Why should such a money supply rule be optimal from the standpoint of central banks and consequently be widely observed? This paper sees the answer in the interaction of price level and nominal interest rate smoothing policies commonly practiced by the world's central banks. Given their responsibility for macroeconomic stabilization, central banks regard price level instability as costly. As custodians of the financial system, central banks cushion nominal interest rates against economic shocks. The paper analyzes a central bank seeking to smooth price level and nominal interest rate movements occasioned by transitory disturbances to money demand, aggregate supply, and the real interest rate. The tension that arises between these objectives induces non-trend-stationary stochastic processes for the price level and the money stock, which is the modern time-series characterization of the previously mentioned stylized fact. Basically, it is desirable for the central bank to regard past money growth, in part, as "bygones" so that the money stock and the price level wander over time without any tendency to return to given growth paths.

${ }^{1}$ Using formal statistical procedures, in a sample of industrialized countries in the post-war period Wasserfallen [1985] cannot, in general, reject the hypothesis that monthly consumer price level and Ml money stock data have no tendency to revert to given growth paths. 
The organization of the remainder of the paper is as follows. In Section II, a simple rational expectations macromodel is laid out and a class of policy rules discussed which contains both trend-stationary and non-trendstationary processes. Central bank preferences for price level and interest rate smoothing are motivated in Section III. In Section IV, the model is solved assuming that the central bank pursues price level smoothing objectives alone. Section $\mathrm{V}$ discusses monetary policy with interest rate smoothing. Issues of definition and mechanics are explored in V-1. Section V-2 demonstrates the "optimality" of a non-trend-stationary money supply rule with interest rate smoothing. Other implications of interest rate smoothing are discussed in Section VI. A brief summary concludes the paper.

\section{THE MACROMODEL}

The analysis is conducted in a simple macromodel. The model includes a goods market equilibrium-interest rate arbitrage condition:

$$
\begin{aligned}
& r_{t}=a_{0}+E_{t+1}^{E} p_{t}-p_{t}+q_{t} \\
& \text { where } \quad E_{t+1} \equiv \text { the period } t \text { mathematical expectation } \\
& \text { of the } 1 \text { og period } t+1 \text { price level } \\
& r_{t} \equiv \text { the period } t \text { nominal interest rate } \\
& \mathrm{P}_{t} \equiv \text { the log period } t \text { price level } \\
& \mathrm{q}_{t} \equiv \text { a serially uncorrelated, zero mean, } \\
& \text { real interest rate disturbance } \\
& a_{0}>0 \text {. }
\end{aligned}
$$

Equation (1) is a zero profit arbitrage condition requiring that the nominal interest rate minus expected inflation equal the goods market clearing real interest rate. The sum $a_{0}+q_{t}$ represents the period $t$ ex ante real rate of 
interest that clears the period $t$ goods market. The $\mathrm{q}_{t}$ term is intended to capture random real interest rate disturbances associated with goods market clearing.

The model includes a money demand function:

$$
\begin{aligned}
& m_{t}^{D}-p_{t}=a_{1}+a_{2} r_{t}+a_{3} y_{t}+v_{t} \\
& \text { where } \quad m_{t}^{D} \equiv \text { the log nominal period } t \text { money stock demanded } \\
& \mathrm{y}_{\mathrm{E}} \equiv \text { the log period } \mathrm{t} \text { real income } \\
& v_{t} \equiv \text { a serially uncorrelated, zero mean, } \\
& \text { money demand disturbance, } \sigma_{\mathrm{qv}}=0 \text {. } \\
& a_{1}>0, a_{2}<0 \text {, and } a_{3}>0 \text {. }
\end{aligned}
$$

Real income is generated by a typical "surprise" aggregate supply function:

$$
\begin{aligned}
& y_{t}=\bar{y}+h\left(p_{t}-E_{t} p_{t}\right)+w_{t} \\
& \text { where } \quad p_{t}-{ }_{t-1} P_{t} \equiv \text { the period } t \text { price level forecast error } \\
& \bar{y} \equiv \text { the mean } \log \text { of real income } \\
& \mathrm{w}_{t} \equiv \text { a serially uncorrelated, zero mean, } \\
& \text { aggregate supply distrubance, } \sigma_{\mathrm{qw}}=\sigma_{\mathrm{vw}}=0 \text {. } \\
& h>0 \text {. }
\end{aligned}
$$

Equation (3) captures the effect of nominally denominated labor contracts which convert price level forecast errors into aggregate real income fluctuations.

Finally, the model includes a simple money supply rule which allows the central bank to choose whether to make the money stock trendstationary or not:

$$
m_{t}^{S}=m_{t-1}+\theta_{1}\left(r_{t}-E_{t-1} r_{t}\right)-\theta_{2}\left(m_{t-1}-E_{t-2} m_{t-1}\right)
$$


where $\quad \mathrm{m}_{t}^{\mathrm{S}} \equiv$ the log nominal period $t$ money stock supplied $\mathrm{m}_{\mathrm{t}-1} \equiv$ the realized $\log$ nominal period $\mathrm{t}-1$ money stock.

The rule includes two policy parameters that the central bank can choose independently. The first, $\theta_{1}$, describes the contemporaneous money stock response to an interest rate innovation. The second, $\theta_{2}$, describes the extent to which the contemporaneous money stock response to an interest rate innovation is offset in the following period. The money supply rule is trend-stationary, i.e., the offset is exact, if and only if $\theta_{2}=1$. Formally, when $\theta_{2}=1$ the money supply rule becomes $m_{t}={ }_{t} E_{2} m_{t-1}+\varepsilon_{t}$, which has the trend-stationary solution $\mathrm{m}_{t}=\overline{\mathrm{m}}+\varepsilon_{t}$, where $\varepsilon_{t}$ is white noise and $\overline{\mathrm{m}}$ is a constant equal to an initial condition on ${ }_{t-2} \mathrm{~m}_{t-1}$. The rule is clearly not trend-stationary if $\theta_{2} \neq 1$. Note that the unit coefficient on the $\mathrm{m}_{t-1}$ term in (4) allows the central bank to make the money stock non-trend-stationary in the simplest sensible way. Coefficients on $m_{t-1}$ that are inside the unit circle automatically imply convergence to a fixed trend, in this case with zero growth, while those outside the unit circle imply explosive money growth.

The money market equilibrium condition closes the model: $m_{t}^{S}=m_{t}^{D}$

Expectations are assumed to be formed rationally. For the monetary authority, expectations are conditioned on information set $I_{t}=\left\{r_{t}, r_{t-1}, \ldots\right.$; $\mathrm{m}_{t}, \mathrm{~m}_{t-1}, \ldots ; \mathrm{p}_{t-1}, \mathrm{p}_{t-2}, \ldots ;$ and $\left.\mathrm{y}_{t-1}, \mathrm{y}_{t-2}, \ldots\right\}$. Individual information sets include observations on current local prices and incomes as well. However, given the model specification, this individual information advantage plays no role in the model's solution. 
where $\quad \mathrm{m}_{t}^{\mathrm{S}} \equiv$ the log nominal period $t$ money stock supplied $\mathrm{m}_{t-1} \equiv$ the realized $\log$ nominal period $t-1$ money stock.

The rule includes two policy parameters that the central bank can choose independently. The first, $\theta_{1}$, describes the contemporaneous money stock response to an interest rate innovation. The second, $\theta_{2}$, describes the extent to which the contemporaneous money stock response to an interest rate innovation is offset in the following period. The money supply rule is trend-stationary, i.e., the offset is exact, if and only if $\theta_{2}=1$. Formally, when $\theta_{2}=1$ the money supply rule becomes $m_{t}={ }_{t} E_{2} m_{t-1}+\varepsilon_{t}$, which has the trend-stationary solution $\mathrm{m}_{t}=\overline{\mathrm{m}}+\varepsilon_{t}$, where $\varepsilon_{t}$ is white noise and $\overline{\mathrm{m}}$ is a constant equal to an initial condition on $t_{t} 2 \mathrm{~m}_{t-1}$. The rule is clearly not trend-stationary if $\theta_{2} \neq 1$. Note that the unit coefficient on the $\mathrm{m}_{t-1}$ term in (4) allows the central bank to make the money stock non-trend-stationary in the simplest sensible way. Coefficients on $m_{t-1}$ that are inside the unit circle automatically imply convergence to a fixed trend, in this case with zero growth, while those outside the unit circle imply explosive money growth.

The money market equilibrium condition closes the model: $m_{t}^{S}=m_{t}^{D}$

Expectations are assumed to be formed rationally. For the monetary authority, expectations are conditioned on information set $I_{t}=\left\{r_{t}, r_{t-1}, \ldots\right.$; $\mathrm{m}_{t}, \mathrm{~m}_{t-1}, \ldots ; \mathrm{p}_{t-1}, \mathrm{p}_{t-2}, \ldots ;$ and $\left.\mathrm{y}_{t-1}, \mathrm{y}_{t-2}, \ldots\right\}$. Individual information sets include observations on current local prices and incomes as well. However, given the model specification, this individual information advantage plays no role in the model's solution. 
The system of equations (1) through (5) determines $p_{t}, r_{t}, m_{t}$, and $y_{t}$ each period as functions of $q_{t}, u_{t} \equiv v_{t}+a_{3} w_{t}, m_{t-1}-t_{t-2} m_{t-1}, m_{t-1}$, and the parameters $a_{0}, a_{1}, a_{2}, a_{3}, \bar{y}, h, \theta_{1}$, and $\theta_{2}$. Quasi solution functions or generating processes for $p_{t}, r_{t}, m_{t}$, and $y_{t}$ are:

$$
\begin{aligned}
p_{t}= & -\left(a_{1}+a_{0} a_{2}+a_{3} \bar{y}\right)+\left[\frac{a_{2}-\theta_{1}}{a_{2}-\theta_{1}-\left(1+a_{3} h\right)\left(1-\theta_{1}\left(1-\theta_{2}\right)\right)}\right] q_{t} \\
& +\left[\frac{1-\theta_{1}\left(1-\theta_{2}\right)}{a_{2}-\theta_{1}-\left(1+a_{3} h\right)\left(1-\theta_{1}\left(1-\theta_{2}\right)\right)}\right] u_{t}-\theta_{2}\left(m_{t-1}-t_{t-2} m_{t-1}\right)+m_{t-1}
\end{aligned}
$$

$$
r_{t}=a_{0}+\left[\frac{-\left(1+a_{3} h\right)}{a_{2}-\theta_{1}-\left(1+a_{3} h\right)\left(1-\theta_{1}\left(1-\theta_{2}\right)\right)}\right] q_{t}+\left[\frac{-1}{a_{2}-\theta_{1}-\left(1+a_{3} h\right)\left(1-\theta_{1}\left(1-\theta_{2}\right)\right)}\right] u_{t}
$$

$$
m_{t}=m_{t-1}+\theta_{1}\left(r_{t}-E_{t-1} r_{t}\right)-\theta_{2}\left(m_{t-1}-E_{t-2} m_{t-1}\right)
$$

$$
y_{t}=\bar{y}+h\left(p_{t}-E_{t} p_{t}\right)+w_{t} \cdot 2
$$

Note that since the money demand level-specified disturbance is transitory, aggregate real money balances are trend-stationary. This implies that the price level is trend-stationary if and only if the nominal money stock is.

\section{CENTRAL BANK PREFERENCES}

The choice of policy parameters $\theta_{1}$ and $\theta_{2}$ is determined by central bank preferences for price level and interest rate smoothing. Central banks prefer smooth price level movements in two senses. As described in equation (3), price level forecast errors have destabilizing employment effects.

2 The generating processes are derived by the method of undetermined coefficients. 
Central banks prefer minimal price level forecast error as a means of stabilizing employment and output. To minimize distortions arising from imperfect indexation of nominally denominated contracts, and expenditure on indexation itself, central banks also prefer minimal variability of expected inflation.

Central banks smooth nominal interest rates to maintain "orderly money markets." Interest rate smoothing minimizes financial market stress due to interest rate prediction errors and associated surprise wealth redistributions. As custodians of the financial system, central banks prefer smooth interest rates to minimize unexpected asset price movements that raise the risk of bankruptcies and banking crises.

In this paper, absence of $\mathrm{q}$ and $\mathrm{u}$ serial correlation and preference for minimal expected inflation variability make it optimal for the central bank to generate serially uncorrelated expected inflation and nominal interest rates. That is why the $\operatorname{IMA}(1,1)$ restriction on the money supply rule is optimal. It follows for the nominal interest rate that forecast error variance is equivalent to unconditional variance, so a nominal interest rate smoothing objective is equivalent to an objective for $\operatorname{Var}\left[\mathrm{r}_{\mathrm{t}}-\mathrm{a}_{0}\right]$

\section{MONETARY POLICY WITH PRICE LEVEL SMOOTHING OBJECTIVES ALONE}

In order to provide a benchmark against which to judge the effects of interest rate smoothing, this section characterizes monetary policy with price level smoothing objectives alone. In this case, $\theta_{1}$ and $\theta_{2}$ are chosen to minimize price level forecast error variance, $\operatorname{Var}\left[\mathrm{p}_{t}-{ }_{t-1} \mathrm{E}_{t}\right]$, and the variance of expected inflation, $\operatorname{Var}\left[\mathrm{E}_{t+1}-\mathrm{p}_{t}\right]$. Using equation (6), the price level forecast error can be written: 
(10)

$$
\begin{aligned}
& p_{t}-{ }_{t-1}^{E} p_{t}=\left[1-\left(1+a_{3} h\right) A\right] q_{t}-A u_{t} \\
& \text { where } \quad A \equiv \frac{\theta_{1}\left(1-\theta_{2}\right)-1}{a_{2}-\theta_{1}-\left(1+a_{3} h\right)\left(1-\theta_{1}\left(1-\theta_{2}\right)\right.} .
\end{aligned}
$$

The value of A that minimizes the price level forecast error variance is:

$$
\begin{gathered}
A^{*} \equiv \frac{\left(1+a_{3} h\right) \sigma_{q}^{2}}{\left(1+a_{3} h\right)^{2} \sigma_{q}^{2}+\sigma_{u}^{2}} \\
\text { where } \quad \sigma_{\mathrm{q}}^{2}, \sigma_{\mathrm{u}}^{2} \equiv \begin{array}{l}
\text { the real interest rate disturbance } \\
\text { variance and the composite money } \\
\text { demand-aggregate supply distur- } \\
\text { bance variance, respectively. }
\end{array}
\end{gathered}
$$

Using equations (6) and (8), expected inflation may be written:

$$
\begin{aligned}
& { }_{t}^{E p_{t+1}}-p_{t}=-\left[1+\left(1+a_{3} h\right) B\right] q_{t}-B u_{t} \\
& \text { where } \quad B \equiv \frac{1}{a_{2}-\theta_{1}-\left(1+a_{3} h\right)\left(1-\theta_{1}\left(1-\theta_{2}\right)\right)} .
\end{aligned}
$$

The value of $B$ that minimizes the variance of expected inflation is:

$$
B * \equiv \frac{-\left(1+a_{3} h\right) \sigma_{q}^{2}}{\left(1+a_{3} h\right)^{2} \sigma_{q}^{2}+\sigma_{u}^{2}} \text {. }
$$

The values of $\theta_{1}$ and $\theta_{2}$ that satisfy conditions (11) and (13) are:

$$
\theta_{1}^{*}=a_{2}+\frac{\sigma_{u}^{2}}{\left(1+a_{3} h\right) \sigma_{q}^{2}} \text { and } \theta_{2}^{*}=1 \text {. }
$$

The value $\theta_{1}^{*}$ represents the optimal contemporaneous money stock response to a nominal interest rate innovation. In Poole's [1970] termi- 
nology, a zero $\theta_{1}^{*}$ is a pure money stock policy. Poole's pure interest rate policy, i.e., a "peg," could be optimal here if the variance of the composite money demand-aggregate supply disturbance vastly exceeded the real interest rate disturbance variance. In general, however, $\theta_{1}^{*}$ is neither zero nor infinite, so that a partial money stock response to a contemporaneous interest rate innovation is optimal. In Poole's words, some combination policy is generally called for.

The interesting feature of the optimal value $\theta_{2}^{*}$ is that it is unity, regardless of the relative size of the real interest rate and money demand disturbance variances. If it is optimal to generate contemporaneous money stock responses to interest rate innovations, i.e., if $\theta_{1}^{*} \neq 0$, then targeted future money growth should respond so that money stock innovations are expected to be offset exactly in the following period. In other words, for monetary policy with price level smoothing objectives alone, the optimal price level and money stock generating processes are trend-stationary.

\section{MONETARY POLICY WITH INTEREST RATE SMOOTHING}

V-1. Definition and Mechanics

As mentioned in Section III, a nominal interest rate smoothing objective is equivalent to an objective for the nominal interest rate variance. The central bank can attain any degree of interest rate smoothing by using (7) to calculate the set of $\left(\theta_{1}, \theta_{2}\right)$ pairs that achieves the desired nominal interest rate variance, and then choosing the $\left(\theta_{1}, \theta_{2}\right)$ pair from that set. The degree of interest rate smoothing should be understood to be zero if the desired interest rate variance matches the variance attained when $\theta_{1}=\theta_{1}^{*}$ and $\theta_{2}=\theta_{2}^{*}$. This definition is natural because policy characterized by the $\left(\theta_{1}^{*}, \theta_{2}^{*}\right)$ pair makes nominal interest rate movements correspond as 
closely as possible to real interest rate movements. ${ }^{4}$ The central bank is engaged in interest rate smoothing if $\left|B^{*}\right|>|B|$, where $B^{*}$ is the value of $B$ associated with $\left(\theta_{1}^{*}, \theta_{2}^{*}\right)$. The degree of interest rate smoothing is inversely related to $|B|$ because the nominal interest rate variance falls with $|B|$.

As is evident from (12), the variance of expected inflation is completely determined once the degree of nominal interest rate smoothing, i.e., B, is chosen. Equation (12) also makes clear that the central bank faces a tradeoff between the expected inflation variance and the nominal interest rate variance. The inverse relation between the two variances is due to the fact that nominal interest rate smoothing is achieved by creating

${ }^{4}$ The monetary authority's conditional expectation of inflation can be expressed as:

$$
\begin{aligned}
& E_{t+1}^{E p_{t}-E_{t}}=-\left[1+\left(1+a_{3} h\right) B\right] E q_{t}-B E u_{t} \\
& \text { where } \quad E_{t}^{E q_{t}}=-\frac{1}{B}\left[\frac{\left(1+a_{3} h\right) \sigma_{q}^{2}}{\left(1+a_{3} h\right)^{2} \sigma_{q}^{2}+\sigma_{u}^{2}}\right]\left(r_{t}-E_{t} E_{1} r_{t}\right) \\
& E_{t}^{E}=-\frac{1}{B}\left[\frac{\sigma_{u}^{2}}{\left(1+a_{3} h\right)^{2} \sigma_{q}^{2}+\sigma_{u}^{2}}\right]\left(r_{t}-E_{t}-1 r_{t}\right) .
\end{aligned}
$$

Substituting for $\underset{t}{E q_{t}}$ and ${ }_{t}^{E} u_{t}$ yields:

$$
E_{t} p_{t+1}-E_{t} p_{t}=\left[\frac{\left[B^{-1}+1+a_{3} h\right]\left(1+a_{3} h\right) \sigma_{q}^{2}+\sigma_{u}^{2}}{\left(1+a_{3} h\right)^{2} \sigma_{q}^{2}+\sigma_{u}^{2}}\right]\left(r_{t}-a_{0}\right) \text {. }
$$

Finally, substituting the optimal $B *$ from (13) into the bracket term above makes it zero. In other words, the objective of minimizing the variance of the public's expected inflation, $\mathrm{Ep}_{t+1}-\mathrm{p}_{t}$, is equivalent to the monetary authority targeting its conditional expectation of inflation at zero. So nominal interest rate movements correspond as closely as possible to real interest rate movements. 
expected inflation or deflation to offset the effect of real interest rate disturbances on the nominal interest rate.

To understand the mechanics of interest rate smoothing, consider the special but revealing case where $\theta_{2}=1$, so that the money supply rule is trend-stationary. Any degree of interest rate smoothing can be achieved by setting $\theta_{1}$ appropriately. So interest rate smoothing per se does not require money stock and price level non-trend-stationarity. However, because $A$ cannot remain equal to $A^{*}$ in (11) when $\theta_{2}=1$ and $\theta_{1}>\theta_{1}^{*}$, interest rate smoothing increases price level forecast error variance when the money supply rule is restricted to be trend-stationary. Essentially, expected inflation or deflation generated to smooth the interest rate increases price level surprises because the expected future price level is anchored at a fixed target. This is the tension, mentioned in the introduction, that induces a central bank to choose a non-trend-stationary money supply rule as described below.

V-2. The "Optimality" of a Non-TrendStationary Money Supply Rule

In this section I derive the "optimal" money supply rule for a central bank that considers price level forecast error and expected inflation variability to be costly, but also views nominal interest rate variability as costly. We may assume that the central bank wishes to minimize the cost function:

$$
\begin{aligned}
& C=\alpha \operatorname{Var}\left[r_{t}-a_{0}\right]+\beta \operatorname{Var}\left[p_{t}-E_{t-1} p_{t}\right]+\gamma \operatorname{Var}\left[E_{t} p_{t+1}-p_{t}\right] \\
& \text { where } \quad \alpha, \beta, \gamma>0 .
\end{aligned}
$$

Using (7), (10), and (12) to express the respective variances as functions of the parameters of the model, (15) can be rewritten: 
(16)

$$
\begin{gathered}
C=\alpha\left[B^{2}\left(\left(1+a_{3} h\right)^{2} \sigma_{q}^{2}+\sigma_{u}^{2}\right)\right]+\beta\left[\left(1-\left(1+a_{3} h\right) A\right)^{2} \sigma_{q}^{2}+A^{2} \sigma_{u}^{2}\right] \\
+\gamma\left[\left(1+\left(1+a_{3} h\right) B\right)^{2} \sigma_{q}^{2}+B^{2} \sigma_{u}^{2}\right] .
\end{gathered}
$$

The central bank's problem is to choose $\theta_{1}$ and $\theta_{2}$, and thereby $A$ and $B$, to minimize (16). The values of $\theta_{1}$ and $\theta_{2}$ that satisfy first-order conditions for a miminum are:

$$
\tilde{\theta}_{1}=a_{2}+\left(1+\frac{\alpha}{\gamma}\right)\left(\frac{1}{1+a_{3} h}\right) \frac{\sigma_{u}^{2}}{\sigma_{q}^{2}} \text { and } \tilde{\theta}_{2}=1+\frac{\alpha}{\gamma}\left(\frac{1}{\tilde{\theta}_{1}}\right) \quad \text { for } \tilde{\theta}_{1} \neq 0
$$

Inspection of $\tilde{\theta}_{1}$ and $\tilde{\theta}_{2}$ in (17) yields two important features of the "optimal" money supply rule. First, $|\tilde{B}|=\left(\frac{\gamma}{\alpha+\gamma}\right)|B *|<|B *|$ so the optimal rule involves interest rate smoothing. Second, if it is optimal to generate contemporaneous money stock responses to interest rate innovations, i.e., if $\tilde{\theta}_{1} \neq 0$, then the optimal rule is not trend-stationary. These features characterize the optimal rule regardless of the relative sizes of $\alpha, \beta$, and $\gamma$. Here is an answer to the question posed in the introduction. The tension between price level and interest rate smoothing does, in fact, induce non-trend-stationary processes for the money stock and the price level. Why? Notice that $\tilde{A}=A^{*}$, so price level forecast error variance continues to be minimized with interest rate smoothing. Basically, it is optimal for central banks to make the expected future money stock and price level respond to current interest rate innovations in order to generate expected inflation and deflation necessary to smooth interest rates without creating price leve1 surprises. 


\section{OTHER IMPLICATIONS OF INTEREST RATE SMOOTHING}

VI-1. Base Drift

During recent years, when the Federal Reserve has targeted money growth it has appeared to accept "base drift" in the level of the money stock when moving from one targeting period to the next. That is, the Federal Reserve has not adjusted its money growth targets to offset money stock innovations as required to hold the money stock to a predetermined trend target path. ${ }^{5}$ The analysis in this paper suggests that the non-trend-stationary money stock behavior may result from tension between price level smoothing and interest rate smoothing objectives that the Federal Reserve simultaneously tries to pursue.

\section{VI-2. Inappropriate Detrending}

If, as argued in this paper, non-trend-stationary price level and money stock generating processes result from typical central bank preferences, the presumption in doing empirical work should be that detrended price level and money stock data are not trend-stationary. A money supply rule making the detrended money stock a function of trend-stationary variables measuring the cyclical state of the economy would be inappropriate, since it forces the non-trend-stationary money stock to be explained by a trend-stationary generating process. 6

5 Broaddus and Goodfriend [1984] document and analyze base drift in detail. Base drift is also discussed in Council of Economic Advisers [1985], pp. 53-4.

${ }^{6} \mathrm{Nelson}$ and Plosser [1982] discuss consequences of misspecification that arise from inappropriate detrending and check for trend-stationarity of some macroeconomic time-series. They also present evidence of non-trendstationarity in U.S. money stock and price level data. 
VI-3. Price Level Forecast Error Variance as the Horizon Recedes

Price level forecast error variance cannot be minimized at all horizons in the presence of nominal interest rate smoothing. Consider equation (18) below, which is derived from (6) and (8):

$$
\operatorname{Var}\left[p_{t+k}-E p_{t+k}\right]=\begin{array}{lc}
{\left[1-\left(1+a_{3} h\right) A\right]^{2} \sigma_{q}^{2}+A^{2} \sigma_{u}^{2}} & \text { for } k=1 \\
{\left[1-\left(1+a_{3} h\right) A\right]^{2} \sigma_{q}^{2}+A^{2} \sigma_{u}^{2}+\left[\left(\theta_{2}-1\right) \theta_{1} B\right]^{2}\left[\left(1+a_{3} h\right)^{2} \sigma_{q}^{2}+\sigma_{u}^{2}\right](k-1)} & \text { for } k>1
\end{array}
$$

With $\theta_{2} \neq 1$, price level forecast error variance rises as the forecast horizon lengthens. With $\theta_{2}=1$, the forecast error variances are equal for all horizons. However, they are minimized only if $\theta_{1}=\theta_{1}^{*}$ as given in (14), which is inconsistent with $\left|\mathrm{B}^{*}\right|>|\mathrm{B}|$ as required for interest rate smoothing. One-period-ahead price level forecast error variance can be minimized with interest rate smoothing, but only if the price level is made non-trendstationary. In that case, the greater the perceived relative costliness of interest rate variability, i.e., $\frac{\alpha}{\gamma}$ in (15), the more steeply price level forecast error variance rises as the horizon recedes.

Consider what this implies for the distribution of prospective real returns on a long-term fixed-rate nominally denominated loan. The variance of the real return associated with such a commitment is minimized in the policy environment of Section IV where monetary policy involves price level smoothing alone. Since price level smoothing alone minimizes price level forecast error at all horizons, it minimizes price level risk associated with the loan. The fixed-rate feature of the loan further insulates its real return from unexpected real interest rate disturbances. In contrast, the real return variance minimizing feature of a long-term fixed-rate 
VI-3. Price Level Forecast Error Variance as the Horizon Recedes

Price level forecast error variance cannot be minimized at all horizons in the presence of nominal interest rate smoothing. Consider equation (18) below, which is derived from (6) and (8):

$$
\operatorname{Var}\left[p_{t+k}-E p_{t+k}\right]=\begin{array}{lc}
{\left[1-\left(1+a_{3} h\right) A\right]^{2} \sigma_{q}^{2}+A^{2} \sigma_{u}^{2}} & \text { for } k=1 \\
{\left[1-\left(1+a_{3} h\right) A\right]^{2} \sigma_{q}^{2}+A^{2} \sigma_{u}^{2}+\left[\left(\theta_{2}-1\right) \theta_{1} B\right]^{2}\left[\left(1+a_{3} h\right)^{2} \sigma_{q}^{2}+\sigma_{u}^{2}\right](k-1)} & \text { for } k>1
\end{array}
$$

With $\theta_{2} \neq 1$, price level forecast error variance rises as the forecast horizon lengthens. With $\theta_{2}=1$, the forecast error variances are equal for all horizons. However, they are minimized only if $\theta_{1}=\theta_{1}^{*}$ as given in (14), which is inconsistent with $\left|\mathrm{B}^{*}\right|>|\mathrm{B}|$ as required for interest rate smoothing. One-period-ahead price level forecast error variance can be minimized with interest rate smoothing, but only if the price level is made non-trendstationary. In that case, the greater the perceived relative costliness of interest rate variability, i.e., $\frac{\alpha}{\gamma}$ in (15), the more steeply price level forecast error variance rises as the horizon recedes.

Consider what this implies for the distribution of prospective real returns on a long-term fixed-rate nominally denominated loan. The variance of the real return associated with such a commitment is minimized in the policy environment of Section IV where monetary policy involves price level smoothing alone. Since price level smoothing alone minimizes price level forecast error at all horizons, it minimizes price level risk associated with the loan. The fixed-rate feature of the loan further insulates its real return from unexpected real interest rate disturbances. In contrast, the real return variance minimizing feature of a long-term fixed-rate 
nominally denominated loan diminishes in the interest rate smoothing environment of Section $V$. With interest rate smoothing, real interest rate disturbances are converted into unexpected price level movements that cumulate over the term of the commitment as non-trend-stationary price level movements.

VI-4. Pegging, Buffering Money Demand Shocks, and the Money Supply Process

The $p, r$, and $m$ generating processes with perfect interest rate smoothing, i.e., a "peg," can be derived by substituting $\tilde{\theta}_{1}$ and $\tilde{\theta}_{2}$ from (17) into (6), (7), and (8) and then letting $\frac{\alpha}{\gamma}$ go to infinity to yield:

$$
\begin{aligned}
p_{t}=-\left(a_{1}+a_{0} a_{2}+a_{3} \bar{y}\right) & +\left[\frac{1}{1-\left(1+a_{3} h\right)\left(1-\hat{\theta}_{2}\right)}\right] q_{t}+\left[\frac{1-\hat{\theta}_{2}}{1-\left(1+a_{3} h\right)\left(1-\hat{\theta}_{2}\right)}\right] u_{t} \\
& -\hat{\theta}_{2}\left(m_{t-1}-E_{t-2} m_{t-1}\right)+m_{t-1}
\end{aligned}
$$

$$
\begin{aligned}
& r_{t}=a_{0} \\
& m_{t}=m_{t-1}+\left[\frac{1+a_{3} h}{1-\left(1+a_{3} h\right)\left(1-\hat{\theta}_{2}\right)}\right] q_{t}+\left[\frac{1}{1-\left(1+a_{3} h\right)\left(1-\hat{\theta}_{2}\right)}\right] u_{t} \\
& -\hat{\theta}_{2}\left(m_{t-1}-E_{t-2} m_{t-1}\right) \\
& \text { where } \quad \hat{\theta}_{2}=\operatorname{Lim}_{\frac{\alpha}{\gamma}+\infty}^{\operatorname{Lim}} \tilde{\theta}_{2}=1+\left(1+a_{3} h\right) \frac{\sigma_{\mathrm{q}}^{2}}{\sigma_{u}^{2}} \text {. }
\end{aligned}
$$

Contrary to conventional thinking in a static context, a peg alone is not sufficient to perfectly buffer the price level and output against money demand shocks (which are contained in $u_{t}$ ). It is necessary that the money supply rule also be trend-stationary, i.e., $\theta_{2}=1$. However, a peg plus trendstationarity does not minimize price level forecast error or the variance of output, since $\hat{\theta}_{2}>1$. In other words, it is inefficient stabilization policy 
to use a peg to buffer output against money demand shocks. In further contrast to conventional thinking in a static context, the money supply is not entirely demand determined under a peg. It depends on the $\theta_{2}$ money supply rule parameter and on other restrictions of the money supply rule. 7

\section{SUMMARY}

Historically, central banks have utilized monetary policy to stabilize both the financial markets and the macroeconomy. To these ends, they have pursued nominal interest rate and price level smoothing policies respectively. This paper has highlighted tension inherent in pursuing these objectives that induces non-trend-stationary processes for the money stock and the price level. The analysis, thereby, contributes to our understanding of the money stock and price level drift that has characterized the post-war era. It also points out that interest rate smoothing must increase both the price level forecast error variance at some horizon and the variability of expected inflation. So interest rate smoothing tends to create macroeconomic instability. In addition, interest rate smoothing and associated non-trendstationary price level policies have implications, outlined in the paper, for macroeconomic time-series analysis, the distribution of prospective real returns on long-term fixed-rate nominally denominated loans, and the operating characteristics of interest rate pegs. The paper has, however, merely identified a constraint across central bank price level and interest rate smoothing objectives. It remains for future research to investigate such issues as the mix of smoothing behavior that is socially optimal.

\footnotetext{
${ }^{7}$ See Dotsey and King [1983] and McCallum [1986] for more on
} interest rate pegs. 
Broaddus, Alfred and Marvin Goodfriend. "Base Drift and the Longer Run Growth of M1: Experience From a Decade of Monetary Targeting." Federal Reserve Bank of Richmond Economic Review. 70 (November/ December 1984): 3-14.

Council of Economic Advisers, Economic Report of the President, Government Printing Office, Washington, D.C., 1985.

Dotsey, Michael and Robert G. King. "Monetary Instruments and Policy Rules in a Rational Expectations Environment." Journal of Monetary Economics. 12 (September 1983): 357-82.

McCallum, Bennett T. "Some Issues Concerning Interest Rate Pegging, Price Level Determinacy, and the Real Bills Doctrine." Journal of Monetary Economics. 17 (January 1986).

Nelson, Charles R. and Charles I. Plosser. "Trends and Random Walks in Macroeconomic Time Series: Some Evidence and Implications." Journal of Monetary Economics. 10 (September 1982): 139-62.

Poole, William. "Optimal Choice of Monetary Policy Instruments in a Simple Stochastic Macro Mode1." Quarterly Journal of Economics. 84 (May 1970) : 197-216.

Wasserfallen, Walter. "Nonstationarities in Macroeconomic Time SeriesFurther Evidence and Implications." Universität Bern, processed, October 1985. 